\title{
Selenium and Vitamin A and E in the Nutrition of Very Low-Birth Weight Preterm Infants
}

\author{
Cleide Enoir Petean Trindade ${ }^{1 *}$ and Lígia Maria Suppo Souza Rugolo ${ }^{2}$
}

${ }^{1}$ Emeritus Professor of Pediatrics, Division of Neonatology, Department of Pediatrics,Botucatu School of Medicine, São Paulo State University-UNESP,São Paulo, Brazil ${ }^{2}$ Associate Professor of Pediatrics, Division of Neonatology, Department of Pediatrics, Botucatu School of Medicine, São Paulo State University-UNESP, São Paulo, Brazil

\begin{abstract}
Deficient antioxidant defenses in preterm infants have been implicated in diseases such as bronchopulmonary dysplasia, retinopathy of prematurity, necrotizing enterocolitis, periventricular leukomalacia, and intraventricular hemorrhage. The antioxidant properties of selenium, vitamin A, and vitamin $E$ make these elements important in the nutrition of Very Low-Birth Weight (VLBW) infants. Selenium is a component of glutathione peroxidase, an enzyme that prevents the production of free radicals. The decrease in plasma selenium in VLBW infants in the first month after birth makes evident that preterm infants have low selenium store and require supplementation by parenteral and enteral nutrition. A meta-analysis, with only three trials, showed that selenium supplementation did not affect mortality, and the incidence of neonatal chronic lung disease or retinopathy of prematurity, but was associated with a reduction in lateonset sepsis. Most VLBW infants and extremely Low-Birth Weight Infants (ELBW) are born with low vitamin A stores and need vitamin A supplementation by intramuscular or enteral route. Low plasma retinol concentrations increase the risk of chronic lung disease/bronchopulmonary dysplasia and long-term respiratory disabilities in preterm infants. There is evidence that vitamin A supplementation decreases the mortality or oxygen requirement at one month of age, and oxygen requirement at 36 weeks' postmenstrual age. Vitamin E blocks natural peroxidation of polyunsaturated fatty acids from lipid layers of cell membranes. VLBW infants have a decrease in plasma concentrations in the first month after birth suggesting the need of vitamin E supplementation. A meta-analysis on vitamin E supplementation concluded that vitamin $\mathrm{E}$ did not affect mortality, risk of bronchopulmonary dysplasia, and necrotizing enterocolitis but reduced the risk of intraventricular hemorrhage and increased the risk of sepsis. Serum vitamin E concentrations higher than $3.5 \mathrm{mg} / \mathrm{dL}$ are associated with a decrease in the risk of severe retinopathy of prematurity, and blindness, but also with an increase in neonatal sepsis. Caution is recommended with the supplementation of high doses of parenteral vitamin $E$ and supplementation that increases serum levels above $3.5 \mathrm{mg} / \mathrm{dL}$. In conclusion: although it is known that preterm infants are deficient in selenium, vitamin $\mathrm{A}$ and $\mathrm{E}$, more studies are required to determine the best way to supplement and the impact of supplementation on neonatal outcome.
\end{abstract}

Keywords: Preterm infant; Micronutrients; Selenium; Vitamin A; Vitamin E

\section{Introduction}

Although studies on fetal and preterm infant nutrition have mainly focused on macronutrients, the investigation on micronutrients, also known as trace elements or oligoelements, especially those with antioxidant effect, is also important since they participate in preterm growth, metabolic functions and disease prevention.

Preterm infants have metabolic characteristics, diseases and complications due to immaturity that make the provision of appropriate nutrients a general concern, as inadequate food intake may have an impact on growth and disease development in later life. Difficulties in the ministration of vitamins and microelements are found because basic needs are not always well defined, variable doses have been used in clinical trials and dosage recommendations vary considerably in the literature [1]. Also, there are no evident clinical signs of deficiency in the neonatal period, so neonatologists are not always aware of the need for supplementation.

An important role has been attributed to some nutrients due to their antioxidant properties, suggesting their possible use in the prevention of diseases whose pathogenesis includes tissue aggression from free radicals and Reactive Oxygen Species (ROS) [2-5]. With this regard, supplementation of trace elements such as selenium, copper, zinc, essential for normal antioxidant enzyme function, and of non enzymatic antioxidant vitamins, such as vitamin $\mathrm{A}$ and $\mathrm{E}$, may be beneficial in decreasing injury from the excess production of ROS, particularly in disorders such as bronchopulmonary dysplasia, retinopathy of prematurity, periventricular leukomalacia and necrotizing enterocolitis [3]. Also, many studies on micronutrients and vitamin supplementation during pregnancy have been undertaken in developing countries aiming at reducing low-birth weight and perinatal and infant mortality, but there are difficulties to analyze results due to different protocols, doses and supplementation time [6]. Although much research on vitamins and microelements were performed in the last years, the optimal dose, route of administration, and real effects remain unclear.

\section{Selenium}

Selenium is one of the essential trace elements in humans. It is an important component of enzymes such as Glutathione Peroxidase $(\mathrm{GPx})$ and iodothyronine 5-deiodinase. GPx is an antioxidant enzyme that prevents the production of free radicals, reducing lipid peroxides and hydrogen peroxide and protecting the organism from

*Corresponding author: Dr. Cleide Enoir Petean Trindade, Professor, Faculty of Medicine of Botucatu, Department of Pediatrics, UNESP, CEP 18618 970 Botucatu-São Paulo-Brazil, Tel/Fax: 55-14-3880-1501; E-mail: cleidet@fmb.unesp.br

Received April 16, 2013; Accepted May 23, 2013; Published May 27, 2013

Citation: Trindade CEP, Rugolo LMSS (2013) Selenium and Vitamin A and E in the Nutrition of Very Low-Birth Weight Preterm Infants. J Neonatal Biol 2: 116 doi:10.4172/2167-0897.1000116

Copyright: (C) 2013 Trindade CEP, et al. This is an open-access article distributed under the terms of the Creative Commons Attribution License, which permits unrestricted use, distribution, and reproduction in any medium, provided the original author and source are credited. 
oxidative aggression. In Very Low-Birth Weight (VLBW) infants, plasma selenium and GPx activity are related to and associated with birth weight. In VLBW infants GPx activity is one-third of the activity observed in term infants. Selenium also plays a role in immunocompetence. Neutrophils and macrophages from seleniumdeficient animals have low glutathione peroxidase concentrations and impaired antimicrobial properties $[7,8]$. The extent of the literature on the essential trace element selenium has increased over the last decade when it was shown that high-Se yeast reduced cancer risk [9].

Selenium concentrations in the soil vary in different regions, and the levels in pastures, animals, and human milk follow these regional variations [10]. The major species of selenium in plant sources are selenate (translocated directly from the soil), selenomethionine (SeMet), small amounts of selenocysteine (SeCys) and different seleno-containing proteins [9]. There is less information on selenium species in dietary sources of animal origin [9]. Human milk has higher selenium concentrations than non-supplemented preterm formulas. The mean selenium content of mature milk from 17 states in the United States is 18 microgram/L [8].

A decrease in blood selenium concentrations is observed in VLBW infants receiving parenteral nutrition without selenium or non-supplemented formulas [11]. Therefore, these formulas are not recommended for preterm infants.

VLBW preterm infants are often subjected to oxygen therapy, which makes them susceptible to oxidative stress and diseases involving free radical aggression. Although selenium deficiency may participate in preterm diseases, there are insufficient data to support this concept. In a review, clinical studies link low blood selenium concentrations and non-selenium supplementation to preterm diseases $[3,8]$. The consequences of low selenium levels in newborns still have to be clarified, although it has been suggested that they represent a risk factor for Chronic Lung Disease (CLD) and Retinopathy of Prematurity (ROP). Studies have focused on antioxidant vitamin $\mathrm{E}$ or selenium as possible preventive strategies for ROP, but systematic reviews of randomized clinical trials have failed to show beneficial effects of supplementation [12]. Also, it is uncertain whether selenium supplementation reduces risk for these diseases. A meta-analysis on selenium supplementation concluded that it only reduced the late onset of sepsis events [13].

\section{Selenium in newborns}

Selenium transfer through the placenta is limited, and fetal concentrations are lower than in mothers, corresponding to approximately $65 \%$ of maternal serum levels. We found no significant differences in cord selenium concentrations between preterm VLBW and term newborns that were appropriate (AGA) or small for gestational age (SGA), and selenium concentrations corresponded to approximately $80 \%$ of maternal level $[12,14]$, although a significant selenium increase in cord blood was described after 36 weeks of gestation [15].

There are no data on fetal selenium content. The estimated incorporation rate is $1 \mathrm{microgram} / \mathrm{kg} / \mathrm{day}$. Selenium is stored in the fetal liver between gestational weeks 20 and 40 , which may determine the low levels found in preterm newborns. Studies on selenium concentration in VLBW preterm infants showed the correlation between selenium, glutathione peroxidase and birth weight $[16,17]$.

\section{Selenium supplementation}

There is a paucity of data about selenium absorption and retention by VLBW preterm infants. The absorption determined by a stable isotope using selenite added to formula concluded that selenium is well absorbed, showing $91 \%$ in non-supplemented formulas and $86 \%$ in supplemented samples [18].

Supplementation studies have compared the bioavailability of different forms of selenium to humans. Organic forms of selenium (wheat-Se, SeMet, and high-Se-yeast) were considered to be more bioavailable than selenate and selenite [9]. Organic selenium (Seyeast) was also more effective than inorganic forms in its ability to transfer selenium to breastfed infants, thus reducing the risk for selenium deficiency [9].

Decrease in selenium concentration was described some decades ago in preterm infants who had respiratory diseases and were receiving parenteral nutrition without selenium supplementation for the first 14 postnatal days, and concentration increased when feeding with selenium-supplemented formula was introduced [19]. Other authors have shown a progressive decline in glutathione peroxidase activity in erythrocyte and plasmatic selenium in preterm newborns from the second postnatal week when they were fed with standard milk formula. Studies on VLBW infants reported that plasma selenium concentrations were lower in infants under parenteral nutrition that was not supplemented with selenium than in supplemented controls [20]. The same was observed when feeding VLBW neonates with preterm formula without selenium. In this study, selenium concentrations were low until the sixth month after birth [21].

We evaluated serum selenium concentrations during the first 30 days after birth in three groups of newborns; VLBW preterm, atterm AGA (at term and adequate for gestational age) and, at-term SGA (at term and small for gestational age). The infants did not receive selenium supplementation in parenteral nutrition, maternal milk fortifier or preterm formula. At-term infants were breastfed or received non- supplemented formula. Cord selenium concentrations were lower than maternal concentrations in the three groups. There were significant differences among the groups, with lower selenium levels in VLBW preterm infants on day 3 after birth as compared to at-term AGA infants, and an accentuated progressive decrease in preterm infants on days 15 and 30 in relation to both at-term groups. In at-term newborns, AGA and SGA, selenium concentrations were stable and not different from those in cord blood levels. Selenium decrease was very precocious, suggesting that preterm infants had low selenium stores and required selenium supplementation in parenteral and enteral nutrition. This study was performed in a region of São Paulo State, Brazil, which has average soil levels of selenium $[3,14]$ (Figure 1).

The necessity to supplement selenium in the nutrition of VLBW infants was shown in different countries. In a multicenter, randomized, double-blind trial, preterm infants were evaluated 28 days after birth and 36 weeks after conception. The treatment group received $7 \mathrm{microgram} / \mathrm{kg}$ per day selenium parenterally and 5 microgram/ $\mathrm{kg}$ per day added to maternal or formula milk. The authors observed that glutathione peroxidase and plasma selenium concentrations were lower in the non-supplemented group at both time points. That study was performed in New Zealand, a country that has very low soil selenium levels [11].

In a randomized study, preterm infants with an average birthweight of $1,171 \mathrm{~g}$ received $3 \mathrm{microgram} / \mathrm{kg}$ per day of selenium supplemented by parenteral nutrition and were followed for the first six weeks after birth [20]. They were compared to preterm infants receiving non-supplemented parenteral nutrition and a reference group of at- 


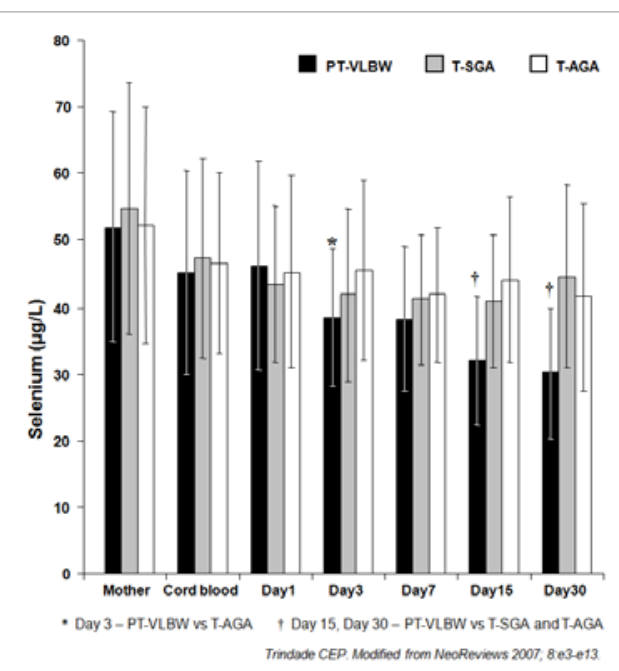

Figure 1: Selenium concentrations in very low-birthweight infants: Median levels in cord blood and newborn blood on days 15 and 30 after birth

term newborns receiving human milk or formula. Supplementation slowed selenium depletion, although it was not enough to attain the concentrations of the at-term breastfed individuals, who had increased selenium levels [20]. That study was performed in Southern Australia, a region that has low selenium soil levels.

In a randomized, controlled trial in the United States, preterm infants were fed preterm infant formula supplemented with 3.5 microgram $/ 100 \mathrm{kcal}$ of selenium, followed by term formula supplemented with 2.6 microgram $/ 100 \mathrm{kcal}$ of selenium. The control group consisted of preterm infants fed preterm formula with 1.2 microgram $/ 100 \mathrm{kcal}$ selenium and then term formula containing 1.3 microgram $/ 100 \mathrm{kcal}$ of selenium up to 12 weeks after birth. Plasma selenium concentrations only declined in the non-supplemented group, although erythrocyte selenium declined in both groups. Also, glutathione peroxidase concentrations only increased in the supplemented group. The authors concluded that selenium supplementation was required in preterm formulas [22].

A decrease in blood selenium concentrations is evident in VLBW infants in parenteral nutrition without selenium or non supplemented preterm formulas $[12,13]$. However, there are questions to be clarified: How much selenium must be added to formulas in order to prevent decrease in blood selenium concentrations in Extremely Low-Birth Weight (ELBW) and VLBW infants? Which is the best selenium chemical form to use as a supplement? what are the limits of toxicity?, and mostly, what is its effectiveness as an antioxidant microelement in the prevention of diseases in which oxidative stress is an important risk factor?

Whether supplementation prevents diseases in newborns still requires further investigation. It must be considered that the main diseases of VLBW infants are multifactorial and selenium deficiency is only one of the risk factors.

In a meta-analysis by Darlow and Austin, three studies fulfilled the requirements and included 297 newborns with supplementation and 290 controls. Two studies included extremely preterm babies. The outcomes were the need for oxygen at 28 days, sepsis episodes, death while in hospital, chronic lung disease (need for oxygen at 28 days and at postconceptual age of 36 weeks), and retinopathy of prematurity. The authors concluded that supplementing VLBW preterm infants with selenium was beneficial in reducing late-onset sepsis. However, there was no effect on mortality, CLD or retinopathy of prematurity. Further studies are recommended on the relationship between selenium and infections in preterm infants [13].

Selenium supplementation in parenteral nutrition and formula is recommended. However, the ideal dose remains undefined. The basic question is whether umbilical cord concentrations or the levels found in breastfed term newborns should be the reference value [14]. Maternal milk may be considered the gold standard for term newborns. Considering that mature human milk has low selenium levels and that preterm infants have a decrease in plasma selenium in the first postnatal month, it is convenient to use fortifiers with added selenium.

In the literature, different amounts of selenium were used as supplement in the nutrition of preterm infants. Data from metaanalyses suggest that the currently recommended dose of selenium for preterm infants receiving parenteral nutrition, 2 micrograms/ $\mathrm{kg}$ per day, is inadequate to maintain cord serum concentrations, while doses of 3 microgram $/ \mathrm{kg}$ per day prevent decline in selenium cord levels. Doses up to 7 microgram $/ \mathrm{kg}$ per day may be required to achieve concentrations above those in cord blood and close to the levels found in healthy breastfed infants. It is important to consider that 7 microgram $/ \mathrm{kg}$ per day is suggested by a study performed in New Zealand, a country with low selenium in the soil [13]. This value is not considered a reference level for all the countries, The American Society for Nutritional Sciences recommends selenium concentrations between 1.8 and 5.0 microgram/100 kcal in formulas for preterm infants [8].

Presently, many preterm milk formulas and milk fortifiers with variable concentrations of supplemented selenium are available to be used for VLBW and ELBW preterm infants. Also solutions for parenteral nutrition with microelements, mostly selenium, are now available.

\section{Vitamin A}

Vitamin A is a group of substances that have vitamin A activity. The term includes retinol, retinaldehyde and retinoic acid. The most important of these substances is retinol, the precursor of metabolically active derivatives. Retinol originates from animal foods or is produced in the organism from beta-carotene found in plants. One molecule of beta-carotene produces two molecules of retinol. Ninety per cent of absorbed retinol is stored in the liver, linked to retinol-binding protein which is transported through plasma bound to transthyretin. Retinol is also found in the retina and the lung.

The vitamin content of a diet is expressed in International Units (IU) or Retinol Activity Equivalent (RAE). One IU of vitamin A is equivalent to $0.3 \mu \mathrm{g}$ of preformed retinol. One RAE of vitamin $\mathrm{A}=1$ microgram. In conclusion, 1 microgram of retinol=3.33 IU.

In the fetus, vitamin $\mathrm{A}$ is important for cell differentiation and lung growth. Vitamin A is involved in the regulation of lung alveolar septation, surfactant production and in maintaining the integrity and regeneration of respiratory epithelial cells [23].

\section{Vitamin A in preterm infants}

The vitamin A concentration of human milk is variable and may be affected by several factors like maternal age, parity, socioeconomic status, time after delivery. Considering that vitamin A from preterm milk is approximately $300 \mathrm{IU} / \mathrm{dL}(90 \mu \mathrm{g} / \mathrm{dL})$, the estimate vitamin intake of a preterm infant feed with $150 \mathrm{~mL} / \mathrm{kg} /$ day of own mother's 
milk is $450 \mathrm{IU} / \mathrm{kg} /$ day $(135 \mu \mathrm{g} / \mathrm{kg} /$ day) [24]. Classic guideline from Greene et al. suggests 700-1500 IU vitamin A/kg/day [25]. Presently, higher doses of 2,000-3,000 have been suggested for infants at risk of chronic lung disease [26].

Lower serum concentrations of vitamin A have been observed in preterm infants during the first months of life, compared to term infants [27]. Most VLBW and ELBW preterm infants are born with low vitamin A stores and the low plasma retinol concentrations increase the risk for developing Chronic Lung Disease (CLD), BPD, and long-term respiratory morbidities, particularly in those with birth weight less than $1,000 \mathrm{~g}[28,29]$. Data from animal studies have linked perturbations of retinol signaling to Congenital Diaphragmatic Hernia (CDH). Retinoic acid, the metabolically active metabolite of retinol, is an important regulator of gene transcription. In humans, a case control study showed that $\mathrm{CDH}$ is strongly associated with low retinol and retinol-binding protein levels in the newborn, independently of maternal retinol status [30].

Since initial studies reported a significantly lower vitamin A status in infants who developed Broncho-Pulmonary Dysplasia (BPD) as compared to infants without BPD [28], many studies on vitamin A supplementation were published.

Studies on vitamin A supplementation suggest that plasma concentrations higher than $20 \mathrm{microgram} / \mathrm{dL}(0.7 \mathrm{micromol} / \mathrm{L})$ indicate vitamin A sufficiency. Low values of vitamin A are defined by plasma concentrations lower than $20 \mathrm{microgram} / \mathrm{dL}$, and deficiency by plasma concentrations less than $10 \mathrm{microgram} / \mathrm{dL}(<0.35 \mathrm{micromol} / \mathrm{L})$ [31]. The relationship between plasma vitamin A concentrations and vitamin A sufficiency is not clear since clinically healthy preterm infants may have concentrations below 20 microgram/dL [32].

\section{Intravenous administration of vitamin $\mathrm{A}$}

Considerable vitamin $\mathrm{A}$ is lost when administered by the parenteral route in a dextrose and amino acid solution because of photo-oxidation ( $16 \%$ lost) and tube adsorption (59\% lost). Only $38 \%$ of the amount administered by the parenteral route is effective. Mixing retinyl palmitate with lipid increases this effectiveness to $90 \%$ [25]. The American Society for Clinical Nutrition recommended 910 $\mathrm{IU} / \mathrm{kg}$ per day ( $280 \mathrm{microgram} / \mathrm{kg} /$ day) in a water soluble mixture ( 1 microgram of equivalent retinol $=3.3 \mathrm{IU}$ ) as the minimum dose suitable for preterm infants $[25,32]$, or $230-500$ per day with the lipid emulsion as recommended by ESPGHAN [33]. However, there is no clear evidence that these doses of supplemented vitamin A improve plasma levels or body stores of vitamin A when administered to VLBW infants. As a single intravenous preparation of vitamin A is not available, it is not possible to increase the standard intravenous dose.

Many VLBW infants and almost all ELBW infants have difficulty to receive an effective enteral nutrition in the first days after birth. The option is the ministration of parenteral nutrition with a mix of vitamins and microelements. Although these multivitamin preparations are available since a long time few significant modifications have been done, and the intravenous vitamin administration is oriented by the newborn weight, without an evaluation of vitamin sufficiency or insufficiency.

\section{Intramuscular administration of vitamin A}

The role of vitamin A in lung epithelial cell differentiation in the fetus has led to the indication of high intramuscular doses of vitamin A to prevent CLD/BPD in preterm infants at risk for these diseases.
A multicenter randomized trial by the National Institute of Child Health and Human Development Neonatal Research Network evaluated 807 ELBW preterm infants who needed respiratory support 24 hours after birth and received vitamin A, 5,000 IU intramuscularly three times a week for 4 weeks. The primary outcome, death or CLD at 36 weeks postconception, was less frequent in the treated group (55\% versus 62\%) [34].

Nine randomized controlled trials evaluated in a Cochrane Systematic Review [35] analyzed the effect of vitamin A supplementation on mortality and morbidity, CLD, BPD, and retinopathy in VLBW preterm infants. Results of the meta-analysis showed that vitamin A supplementation appears to be beneficial in reducing death or oxygen requirement at one month of age and oxygen requirement at 36 week postmenstrual age. However, in a trial on ELBW preterm infants who received 10,000 IU intramuscularly, three times a week or 15,000 IU once a week, no differences were observed in the incidence of death/BPD or death at 36 weeks postconception when compared with a standard retinol dose (5,000 IU three times a week) [36]. This dose does not seem to affect neurodevelopmental outcomes at 18 to 24 months [37].

The optimal intramuscular dose is still unclear. Although the current recommendations are to give 5,000 UI intramuscular vitamin A three times a week for 4 weeks (12 total doses) to infants with birth weight less than $1,000 \mathrm{~g}$ [38] it has not been widely used [32]. Limiting factors are the large number of intramuscular injections, the consequent pain and invasiveness of the procedure, and the modest benefits in the respiratory system [32]. In a Cochrane Database Systematic Review, Darlow and Graham [35] suggest that the decision to use repeated intramuscular doses of vitamin A to prevent chronic lung disease may depend upon the local incidence of this outcome and the importance attached to achieving a modest reduction, balanced against the lack of other proven benefits and the acceptability of treatment.

\section{Oral administration of vitamin A}

VLBW infants, and particularly those with less than 1,000 g, require vitamin A supplementation. However, it is difficult to attain vitamin A sufficiency as they are born with inadequate body stores, and frequently they do not tolerate routine oral nutrition.

The American Academy of Pediatrics recommends for preterm infants an intake of 210 to 450 microgram per $\mathrm{kg} / \mathrm{day}$ of retinol [31]. Ingestion of less than $700 \mathrm{IU} / \mathrm{kg}$ per day ( $<250$ microgram $/ \mathrm{kg} /$ day) is associated with an accentuated decline in plasma vitamin A concentration [24].

In term neonates, vitamin $\mathrm{A}$ is well absorbed by the enteral route and can be given orally. In VLBW infants, vitamin A (5,000 IU/ day), given orally with early feeds, can result comparable to plasma concentrations of retinol given intramuscularly (2,000 IU on alternate days) [39]. Salle et al. recommend for preterm infants, 5,000 IU/day or $4,000 \mathrm{IU} / \mathrm{kg} /$ day during 4 to 5 weeks to attain normal plasmatic values, and 3,000 IU/day up to six months to maintain normal concentrations [40].

In our neonatal division, oral supplementation of 5,000 IU/day for VLBW preterm infants is routinely used after the first week after birth. To evaluate retinol concentration in this feeding regimen, we prospectively determined plasma retinol from maternal blood, at the moment of delivery, and from 22 VLBW newborns (non-BPD versus BPD groups) from birth up to 30 days after birth [3,41]. Plasma retinol 
concentration was evaluated as a function of total vitamin A received in parenteral nutrition, from milk and as an oral supplement $(5,000$ IU/day). Plasma concentrations on day 3 , in both groups, remained similar to their umbilical cord values (non-BPD, $24.93 \mu \mathrm{g} / \mathrm{dL}$; BPD, $26.07 \mu \mathrm{g} / \mathrm{dL}$ ), except on day 14 , when both groups had maximum peak values (non-BPD 40,40 $\mu \mathrm{g} / \mathrm{dL}$; BPD $59.88 \mu \mathrm{g} / \mathrm{dL}$ ) and high values on day 28 in the BPD group $(41.26 \mu \mathrm{g} / \mathrm{dL})$. Vitamin A administration in the non-BPD group was exclusively by enteral route at an average of 3,606 IU/kg per day from the second to fourth week, and in the BPD group was $868 \mathrm{IU} / \mathrm{kg}$ per day for the second week exclusively by parenteral route, and $1,660 \mathrm{IU} / \mathrm{kg}$ per day in the third and fourth weeks, with $20 \%$ by the parenteral route. Only $15 \%$ of the infants weighed less than $1,000 \mathrm{~g}$. These results showed that in 1,000 to 1,500 g birthweight newborns, parenterally administered vitamin A with lipid, together or followed by high doses of vitamin A by the gastric route, produced normal to elevated plasma vitamin-A concentrations. Due to small sample size, we could not conclude about the influence of vitamin A on BPD frequency [3,41] (Figure 2).

A different result was reported in a randomized controlled trial, in which preterm infants less than 1,000g received 5,000 IU/kg per day of vitamin A by an orogastric tube. Plasma vitamin A concentrations were higher only $24 \mathrm{~h}$ after birth, but at birth, 12 hours, 7 days, and 28 days after birth, plasma concentrations were not different from those in control. Also, $50 \%$ of the supplemented group had, at 28 days after birth, plasma vitamin A less than $20 \mu \mathrm{g} / \mathrm{dL}(0.7 \mu \mathrm{mol} / \mathrm{L})$, and suggesting vitamin A insufficiency [42]. Extremely low-birth weight infants must be supplemented by the parenteral or intramuscular route since even large enteral doses do not increase plasma concentrations to normal levels [32].

\section{Vitamin E}

Vitamin $\mathrm{E}$ is a generic term including eight lipid-soluble compounds. Vitamin E comprises a group of four tocols, and four toco-trienols. Most active, alpha-tocopherol, makes up $90 \%$ of the vitamin $\mathrm{E}$ found in human tissue. The commercial forms, alphatocopherol acetate or succinate, are more stable than natural alphatocopherol.

Vitamin $\mathrm{E}$ is found in all tissues, where it acts as an antioxidant and free radical scavenger. It blocks the natural peroxidation of Polyunsaturated Fatty Acids (PUFAs) found in lipid layers of cellular

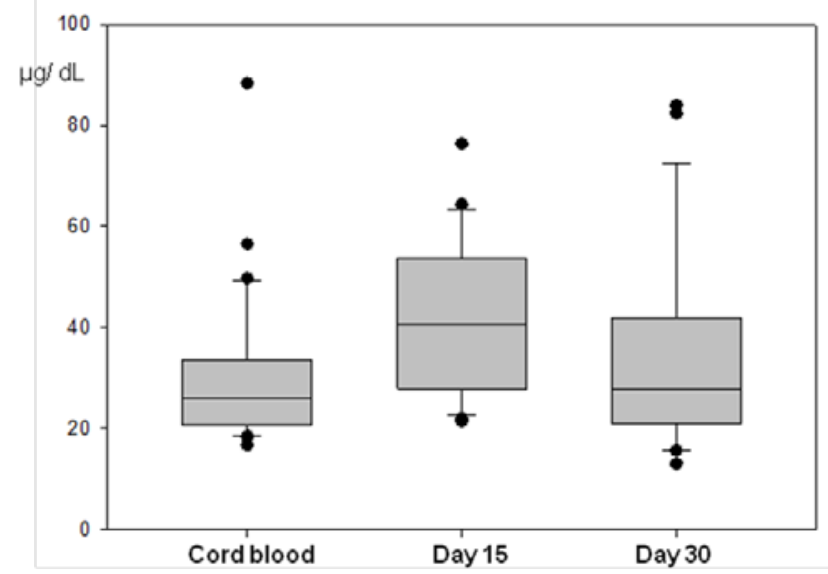

Figure 2: Vitamin A concentrations in very low-birthweight infants: Median levels in cord blood and newborn blood on days 15 and 30 after birth.

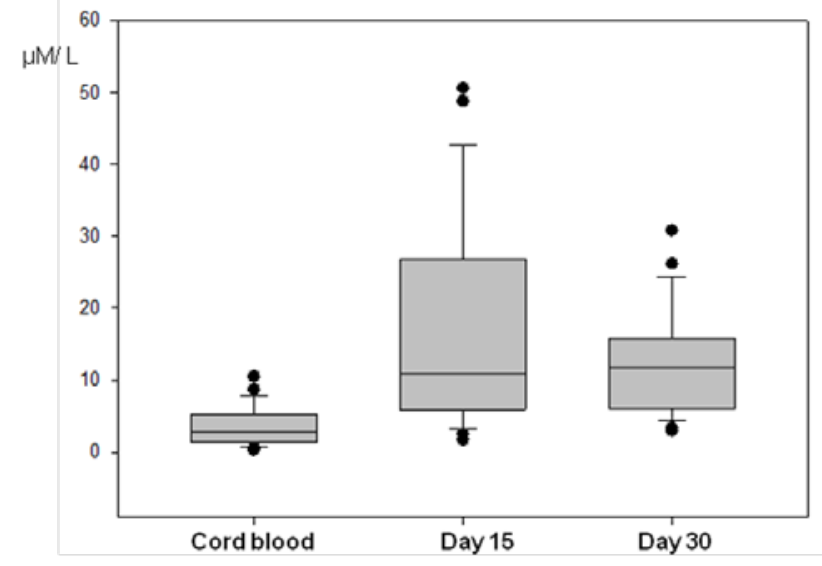

Figure 3: Vitamin E concentrations in very low-birthweight infants: Median levels in cord blood and newborn blood on days 15 and 30 after birth.

membranes. Lipid peroxidation starts when an atom of hydrogen escapes the double bond of one of the lipid carbons, causing an intermediate situation that is highly favorable to reaction with an oxygen free radical. The resultant lipid free radical interacts with another PUFA, originating a stable lipid hydroperoxide and another lipid free radical, triggering an autocatalytic chain reaction. Vitamin E blocks this chain reaction by substituting the oxygen and stabilizing the hydrogen reaction of the lipid free radical. In this process, alphatocopherol is transformed into alpha-tocopheryl quinone, which is excreted in urine as malondialdehyde, pentane, and ethane. This vitamin $\mathrm{E}$ function is very important to maintain the integrity of growing tissues, particularly for preterm infants [43,44].

\section{Vitamin $\mathrm{E}$ and preterm newborn}

Low vitamin E concentrations are found in fetal tissues and appreciable prenatal vitamin $\mathrm{E}$ accretion occurs in the third trimester of pregnancy with increasing fetal lipid stores. The way how vitamin $\mathrm{E}$ crosses the placenta is still unknown. Studies that have investigated the influence of maternal concentration of alpha-tocopherol on neonatal concentrations were inconclusive, and data suggest that the transfer of vitamin $\mathrm{E}$ from the mother to the fetus may be limited. Studies have demonstrated that vitamin E concentrations in cord blood are lower than in maternal blood [45] and so has our experience (Figure 3).

The American Academy of the Pediatric Committee on Nutrition proposes that safe and effective serum concentrations of vitamin $\mathrm{E}$ are between 23 and 46 micromol/L ( 1 and $2 \mathrm{mg} / \mathrm{dL}$ ) Plasma concentration of alpha-tocopherol depends on the quantity of lipids due to its association with plasma lipoproteins. As a result, preterm infants have lower vitamin E levels than term newborns and both have lower concentrations than adults. It is better to express concentration in relation to beta-lipoprotein, cholesterol or total lipids. Several authors consider an alpha-tocopherol/total lipid ratio less than $0.8 \mathrm{mg} / \mathrm{g}$ to be indicative of vitamin deficiency $[44,46]$. However, Salle et al. suggest 1.9 for infants and 0.8 for adults (mg alpha-tocopherol/g of lipids [43].

\section{Recommendations for vitamin $\mathrm{E}$}

Vitamin $\mathbf{E}$ in enteral nutrition: Human milk has antioxidant capacity that is represented by various bioactive components with specific antioxidant functions against lipid peroxidation. This antioxidant capacity is attributed mostly to alpha-tocopherol concentration [47]. 
Vitamin-E concentration in colostrum and preterm human milk is two times higher than in mature term milk, with a mean concentration of $1.9 \mathrm{IU} / 100 \mathrm{kcal}$, and an E/PUFA ratio of 2.0 in the first week. The concentration decreases to about $0.9 \mathrm{IU} / \mathrm{kcal}$ in the fourth postnatal week [46]. Although it was referred that preterm infants, fed their own mother's milk, tocopherol content of about $1.2 \mathrm{mg} / 100$ $\mathrm{kcal}$, have adequate vitamin $\mathrm{E}$ status without additional vitamin $\mathrm{E}$ supplementation, Delvin et al. showed that oral supplementation of 5 mg of vitamin E (11.6 micromol) per day for 90 days, increased plasma vitamin $\mathrm{E}$ in exclusively breast-fed and formula-fed preterm infants. In spite of supplementation they did not achieve characteristic plasma concentrations of the repletion status $[48,49]$.

Comparing vitamin E concentrations between breast-fed preterm infants supplemented with vitamin $\mathrm{E}$ and term infants at 1 week of age and at discharge, there was no significant difference in the plasma concentration of alpha-tocopherol in VLBW infants at discharge and term infants at 4 weeks of age. Plasma tocopherol levels were within the reference range $(14-50 \mu \mathrm{M})$. Dietary intake was estimated from parenteral nutrition, human milk, formulas and oral supplements ( $2 \mathrm{mg}$ per day as an oral multivitamin plus $15 \mathrm{mg} /$ day as alphatocopherol) [50]. In 2002, the Expert Panel of the American Society for Nutritional Sciences recommended a minimum of $2 \mathrm{mg}$ and a maximum of $8.0 \mathrm{mg}$ alpha-tocopherol/100 kcal in preterm infant formulas, and the vitamin E/PUFA ratio (mg alpha-tocopherol/g total PUFA) should exceed $1.5 \mathrm{mg} / \mathrm{g}$ [8].

Vitamin E in parenteral nutrition: Before attaining full enteral nutrition, vitamin E must be supplied in parenteral nutrition at doses of 2.8 to $3.5 \mathrm{IU} / \mathrm{kg}$ per day to maintain alpha-tocopherol plasma concentrations around 1 to $2 \mathrm{mg} / \mathrm{dL}$ [51]. The American Society for Clinical Nutrition recommends $2.8 \mathrm{IU} / \mathrm{Kg} /$ day with a maximum dose of $7 \mathrm{IU} /$ day. Dose of $2.8 \mathrm{IU} / \mathrm{kg} /$ day correspond to $2 \mathrm{~mL} / \mathrm{kg} /$ day of a standard intravenous multivitamin (MVI Pediatric) with DL-alphatocopheryl acetate [52]. Authors recommend checking serum alphatocopherol levels in infants receiving doses higher than $4 \mathrm{IU} / \mathrm{kg} / \mathrm{day}$ intravenously for more than 2 weeks, as the therapeutic-to-toxic ratio is very narrow [52].

Considering the toxic effects of high doses of intravenous vitamin-E supplementation in preterm infants, doses aiming at serum tocopherol levels greater than $3.5 \mathrm{mg} / \mathrm{dL}$ are not recommended [53]. There are also reports of increased sepsis and necrotizing enterocolitis with intravenous or oral administration associated with plasma tocopherol levels of $4.8 \mathrm{mg} / \mathrm{dL}$ [53].

In an important systematic review of twenty six randomized trials on vitamin E supplementation in preterm infants and the prevention of mortality and morbidity, the most important conclusions for VLBW infants were that vitamin E supplementation did not affect mortality, risk for BPD and necrotizing enterocolitis [53]. The authors observed that vitamin E supplementation reduced the risk for germinal matrix/intraventricular hemorrhage, but increased the risk for sepsis in VLBW newborns, mainly when the vitamin E dose was more than $30 \mathrm{IU} / \mathrm{kg}$ per day, and serum tocopherol concentrations were greater than $3.5 \mathrm{mg} / \mathrm{dL}$. Vitamin E supplementation reduced the risk for severe retinopathy of prematurity and blindness, but only when serum vitamin $\mathrm{E}$ concentrations were higher than $3.5 \mathrm{mg} / \mathrm{dL}$. For VLBW newborns, the evidence was against using high doses of vitamin $\mathrm{E}$ by the parenteral route or supplementation that elevated serum levels above $3.5 \mathrm{mg} / \mathrm{dL}$ (81.3 micromol/L) [53].

\section{Is it justifiable to supplement vitamin E for VLBW infants?}

There is a paucity of studies evaluating vitamin E levels in VLBW infants and the relationship with dietary intake, the supplemental amount and the sufficiency of supplementation. It is difficult to compare the studies because infants are treated with different diets, and in the last decades human milk fortifiers and modifications in preterm formulas have been introduced in different countries. In our service plasma tocopherol concentration was evaluated in 28 mothers at delivery and their VLBW infants from the moment of delivery, day 14 and day 28 . The babies were fed maternal milk plus human milk fortifier, preterm formula and parenteral nutrition with added vitamin E. The estimated mean intake of vitamin E $(\mathrm{mg} / \mathrm{kg} /$ day) was calculated in two periods: D1-D14 and D15-D28. Plasma concentrations of alpha-tocopherol (median and percentiles) from cord blood, $2.66(1.3,4.89) \mu \mathrm{mol} / \mathrm{L}$ were significantly lower than in maternal blood, $19.07(16.95,22.25) \mu \mathrm{mol} / \mathrm{L}$. The vitamin E intake in the first period was $2.20 \mathrm{mg} / \mathrm{kg} /$ day and in the second period $4.87 \mathrm{mg} /$ $\mathrm{kg} /$ day. The levels increased in the first month after birth although they did not attain the reference values for tocopherol. Although the intake per $\mathrm{kg} /$ day from day 14 to 28 is considered adequate, the low plasma concentration of tocopherol on day 28 (mean $10.81 \mu \mathrm{mol} / \mathrm{L}$ ) is considered a deficient level (Figure 3) (article in publication). These data suggest that VLBW infants need supplementation, especially those infants born from mothers that have low concentrations of vitamin E. Further research is necessary to define the dose and time of supplementation to attain the vitamin E repletion state in VLBW and ELBW infants (for Publication).

\section{Conclusion}

Although it is known that preterm infants are deficient in selenium, vitamin $\mathrm{A}$ and $\mathrm{E}$, more studies are needed to determine the best way to supplement and the impact of supplementation on neonatal outcome.

\section{References}

1. Westergren T, Kalikstad B (2010) Dosage and formulation issues: oral vitamin E therapy in children. Eur J Clin Pharmacol 66: 109-118.

2. Robles R, Palomino N, Robles A (2001) Oxidative stress in the neonate. Early Hum Dev 65 Suppl: S75-S81.

3. Trindade CEP (2007) Microelements and vitamins in the nutrition of very lowbirthweight preterm infants: A Brazilian perspective. Neo Reviews 8: e3-e13.

4. Davis JM, Auten RL (2010) Maturation of the antioxidant system and the effects on preterm birth. Semin Fetal Neonatal Med 15: 191-195.

5. Lee JW, Davis JM (2011) Future applications of antioxidants in premature infants. Curr Opin Pediatr 23: 161-166.

6. Castillo-Durán C, Weisstaub G (2003) Zinc supplementation and growth of the fetus and low birth weight infant. J Nutr 133: 1494S-7S.

7. Aggett PJ (2000) Trace elements of the micropremie. Clin Perinatol 27: 119 129 .

8. Klein CJ (2002) Nutrient requirements for preterm infant formula. J Nutr 132: 1395S-577S.

9. Rayman MP, Infante HG, Sargent M (2008) Food-chain selenium and human health: spotlight on speciation. Br J Nutr 100: 238-253.

10. Dorea JG (2002) Selenium and breast-feeding. Br J Nutr 88: 443-461.

11. Darlow BA, Winterbourn CC, Inder TE, Graham PJ, Harding JE, et al. (2000) The effect of selenium supplementation on outcome in very low birth weight infants: a randomized controlled trial. The New Zealand Neonatal Study Group. J Pediatr 136: 473-480.

12. Trindade CEP, Rugolo LMSS (2007) Free Radicals and Neonatal Diseases. Neo Reviews 8: e522-e532.

13. Darlow BA, Austin NC (2003) Selenium supplementation to prevent short-term morbidity in preterm neonates. Cochrane Database Syst Rev: CD003312.

14. Daher S, Trindade CEP, Rezende C, Miranda A, Crossi R (2001) Blood 
Citation: Trindade CEP, Rugolo LMSS (2013) Selenium and Vitamin A and E in the Nutrition of Very Low-Birth Weight Preterm Infants. J Neonatal Biol 2: 116. doi:10.4172/2167-0897.1000116

selenium levels of very low birth weight infants during the first month of life. Pediatr Res 49: 297A.

15. Makhoul IR, Sammour RN, Diamond E, Shohat I, Tamir A, et al. (2004) Selenium concentrations in maternal and umbilical cord blood at 24-42 weeks of gestation: basis for optimization of selenium supplementation to premature infants. Clin Nutr 23: 373-381.

16. Lockitch G, Jacobson B, Quigley G, Dison P, Pendray M (1989) Selenium deficiency in low birth weight neonates: an unrecognized problem. J Pediatr 114: 865-870.

17. Nassi N, Ponziani V, Becatti M, Galvan P, Donzelli G (2009) Anti-oxidant enzymes and related elements in term and preterm newborns. Pediatr Int 51: 183-187.

18. Ehrenkranz RA, Gettner PA, Nelli CM, Sherwonit EA, Williams JE, et al. (1991) Selenium absorption and retention by very-low-birth-weight infants: studies with the extrinsic stable isotope tag 74Se. J Pediatr Gastroenterol Nutr 13: 125-133.

19. Amin S, Chen SY, Collipp PJ, Castro-Magana M, Maddaiah VT, et al. (1980) Selenium in premature infants. Nutr Metab 24: 331-340.

20. Daniels L, Gibson R, Simmer K (1996) Randomised clinical trial of parenteral selenium supplementation in preterm infants. Arch Dis Child Fetal Neonatal Ed 74: F158-164

21. Sievers E, Arpe T, Schleyerbach U, Garbe-Schönberg D, Schaub J (2001) Plasma selenium in preterm and term infants during the first 12 months of life. $\mathrm{J}$ Trace Elem Med Biol 14: 218-222.

22. Tyrala EE, Borschel MW, Jacobs JR (1996) Selenate fortification of infant formulas improves the selenium status of preterm infants. Am J Clin Nutr 64 860-865.

23. Zachman RD (1989) Retinol (vitamin A) and the neonate: special problems of the human premature infant. Am J Clin Nutr 50: 413-424.

24. Shenai JP (1993) Vitamin A. In Tsang RC, Lucas A, Uauy R, Zlotkin S editors. Nutritional needs of the Preterm infant. Scientific basis and practical guidelines. Cincinatti, $\mathrm{OH}$. Williams \& Wilkins $\mathrm{p}$ 87-100.

25. Greene HL, Hambidge KM, Schanler R, Tsang RC (1988) Guidelines for the use of vitamins, trace elements, calcium, magnesium, and phosphorus in infants and children receiving total parenteral nutrition: report of the Subcommittee on Pediatric Parenteral Nutrient Requirements from the Committee on Clinical Practice Issues of the American Society for Clinical Nutrition. Am J Clin Nutr 48: 1324-1342.

26. Mactier H (2013) Vitamin A for preterm infants; where are we now? Semin Fetal Neonatal Med

27. Brandt RB, Mueller DG, Schroeder JR, Guyer KE, Kirkpatrick BV, et al. (1978) Serum vitamin A in premature and term neonates. J Pediatr 92: 101-104.

28. Shenai JP, Chytil F, Stahlman MT (1985) Liver vitamin A reserves of very low birth weight neonates. Pediatr Res 19: 892-893.

29. Spears K, Cheney C, Zerzan J (2004) Low plasma retinol concentrations increase the risk of developing bronchopulmonary dysplasia and long-term respiratory disability in very-low-birth-weight infants. Am J Clin Nutr 80: 1589-1594.

30. Beurskens LW, Tibboel D, Lindemans J, Duvekot JJ, Cohen-Overbeek TE, et al. (2010) Retinol status of newborn infants is associated with congenital diaphragmatic hernia. Pediatrics 126: 712-720.

31. Atkinson SA (2001) Special nutritional needs of infants for prevention of and recovery from bronchopulmonary dysplasia. J Nutr 131: 942S-946S.

32. Mactier H, Weaver LT (2005) Vitamin A and preterm infants: what we know what we don't know, and what we need to know. Arch Dis Child Fetal Neonatal Ed 90: F103-F108

33. ESPGHAN (2005) 8 Vitamins. J Pediat Gastroenterol Nutr 41:S47-S53.

34. Tyson JE, Wright LL, Oh W, Kennedy KA, Mele L, et al. (1999) Vitamin A supplementation for extremely-low-birth-weight infants. National Institute of Child Health and Human Development Neonatal Research Network. N Engl J Med 340: 1962-1968.

35. Darlow BA, Graham PJ (2011) Vitamin A supplementation to prevent mortality and short-and long-term morbidity in very low birthweight infants. Cochrane Database of Systematic Reviews: CD000501.
36. Ambalavanan N, Wu TJ, Tyson JE, Kennedy KA, Roane C, et al. (2003) A comparison of three vitamin $A$ dosing regimens in extremely-low-birth-weight infants. J Pediatr 142: 656-661.

37. Ambalavanan N, Tyson JE, Kennedy KA, Hansen NI, Vohr BR, et al. (2005) Vitamin A supplementation for extremely low birth weight infants: outcome at 18 to 22 months. Pediatrics 115: e249-e254.

38. Biniwale MA, Ehrenkranz RA (2006) The role of nutrition in the prevention and management of bronchopulmonary dysplasia. Semin Perinatol 30: 200 208

39. Landman J, Sive A, Heese HD, Van der Elst C, Sacks R (1992) Comparison of enteral and intramuscular vitamin A supplementation in preterm infants. Early Hum Dev 30: 163-170.

40. Salle BL, Delvin E, Claris O, Hascoet JM, Levy E (2007) [Is it justifiable to administrate vitamin $A, E$ and $D$ for 6 months in the premature infants?]. Arch Pediatr 14: 1408-1412.

41. Rugolo A Jr, Miranda AF, Rugolo LMSS, Padovani C, Trindade CEP (2003) Blood retinol levels of very low birth weight infants and its relationship with bronchopulmonary dysplasia. Pediatr Res 53: 408A

42. Wardle SP, Hughes A, Chen S, Shaw NJ (2001) Randomised controlled tria of oral vitamin A supplementation in preterm infants to prevent chronic lung disease. Arch Dis Child Fetal Neonatal Ed 84: F9-9F13.

43. Salle BL, Delvin E, Claris O (2005) [Fat-soluble vitamins in infants]. Arch Pediatr 12: 1174-1179.

44. Biesalski HK (2009) Vitamin E requirements in parenteral nutrition. Gastroenterology 137: S92-S104.

45. Baydas G, Karatas F, Gursu MF, Bozkurt HA, Ilhan N, et al. (2002) Antioxidant vitamin levels in term and preterm infants and their relation to materna vitamin status. Arch Med Res 33: 276-280.

46. Gross JS (1993) Vitamin E In: Tsang R, Lucas A, Uauy R, Zlotkin S Nutritiona Needs of the Preterm Infant. Scientific Basis and Practical Guidelines. (1st ed) Willians \& Wilkins, Baltmore.

47. Tijerina-Sáenz A, Innis SM, Kitts DD (2009) Antioxidant capacity of human milk and its association with vitamins $A$ and $E$ and fatty acid composition. Acta Paediatr 98: 1793-1798.

48. Kaempf DE, Linderkamp O (1998) Do healthy premature infants fed breast milk need vitamin E supplementation: alpha- and gamma-tocopherol levels in blood components and buccal mucosal cells. Pediatr Res 44: 54-59.

49. Delvin EE, Salle BL, Claris O, Putet G, Hascoet JM, et al. (2005) Oral vitamin $A, E$ and $D$ supplementation of pre-term newborns either breast-fed or formula-fed: a 3-month longitudinal study. J Pediatr Gastroenterol Nutr 40: 43-47.

50. Henriksen C, Helland IB, Rønnestad A, Grønn M, Iversen PO, et al. (2006) Fat-soluble vitamins in breast-fed preterm and term infants. Eur $\mathrm{J}$ Clin Nutr 60: 756-762.

51. Greer FR (2000) Vitamin metabolism and requirements in the micropremie. Clin Perinatol 27: 95-118, vi.

52. Brion LP, Bell EF, Raghuveer TS, Soghier L (2004) What is the appropriate intravenous dose of vitamin $E$ for very-low-birth-weight infants? J Perinato 24: $205-207$

53. Brion LP, Bell EF, Raghuveer TS (2003) Vitamin E supplementation fo prevention of morbidity and mortality in preterm infants. Cochrane Database Syst Rev: CD003665. 